\title{
Facile conversion from biologic to mechanical prosthesis: A bailout for a hostile aortic root
}

\author{
Phillip G. Rowse, MD, ${ }^{\mathrm{a}}$ Alexander C. Egbe, MD, MPH, ${ }^{\mathrm{b}}$ and Sameh M. Said, MD, ${ }^{\mathrm{a}}$ Rochester, Minn
}

\footnotetext{
From the ${ }^{\mathrm{a}}$ Department of Cardiovascular Surgery, and ${ }^{\mathrm{b}}$ Division of Cardiovascular Diseases, Mayo Clinic, Rochester, Minn.

Disclosures: Authors have nothing to disclose with regard to commercial support.

Received for publication July 18, 2017; revisions received Oct 16, 2017; accepted for publication Nov 1, 2017; available ahead of print Dec 2, 2017

Address for reprints: Sameh M. Said, MD, Department of Cardiovascular Surgery, Mayo Clinic, 200 First St SW, Rochester, MN 55905 (E-mail: said.sameh@mayo.edu).

J Thorac Cardiovasc Surg 2018;155:e179-81

$0022-5223 / \$ 36.00$

Copyright (c) 2017 by The American Association for Thoracic Surgery

https://doi.org/10.1016/j.jtcvs.2017.11.004
}

Video clip is available online.

Left ventricular outflow tract obstruction as a result of early prosthetic aortic valve (AV) failure can present a complex reoperative problem, especially in the presence of a hostile aortic root. We present a case of seventh-time sternotomy for re-replacement of the $\mathrm{AV}$ with a less conventional approach.

\section{CLINICAL SUMMARY}

A 31-year-old man with an extensive surgical history related to congenital bicuspid aortic stenosis presented with symptomatic severe recurrent prosthetic AV dysfunction (effective orifice area, $0.87 \mathrm{~cm}^{2}$; mean systolic gradient, $73 \mathrm{~mm} \mathrm{Hg}$ ). His surgical history included: (1) balloon valvuloplasty at birth, followed by repeated valvuloplasty at 2 years of age; (2) surgical aortic valvotomy at 2 years of age; (3) Konno-Rastan aortoventriculoplasty with AV replacement with a 19-mm St Jude mechanical prosthesis (St Jude Medical, St Paul, Minn) at 8 years of age.

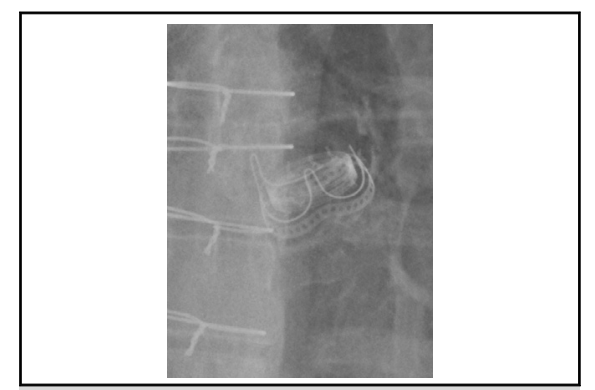

Magnified view of the valve-on-valve observed on a chest roentgenogram.

Central Message

Re-recurrent LVOT obstruction after prosthetic $\mathrm{AV}$ replacement is a complex issue. If the root is hostile, a surgical valve-on-valve technique is a viable alternative to extensive reconstruction.

See Editorial Commentary page e183.

age; (4) reoperative AV and root replacement with 21-mm Medtronic Freestyle bioprosthesis (Medtronic, Minneapolis, Minn) at 12 -years of age; (5) redo AV replacement with 23-mm bioprosthesis at 12 years of age for significant periprosthetic regurgitation; (6) redo AV replacement with 25-mm Carpentier-Edwards bioprosthesis (Edwards Lifesciences Corp, Irvine, Calif), aortic root revision with patch augmentation, and septal myectomy at 20 years of

The decision was made to pursue a seventh sternotomy and AV and aortic root re-replacement with a mechanical prosthesis. Dense calcification of the root, as identified on preoperative computed tomographic angiography of the chest (Figure 1, A) ultimately precluded consideration of

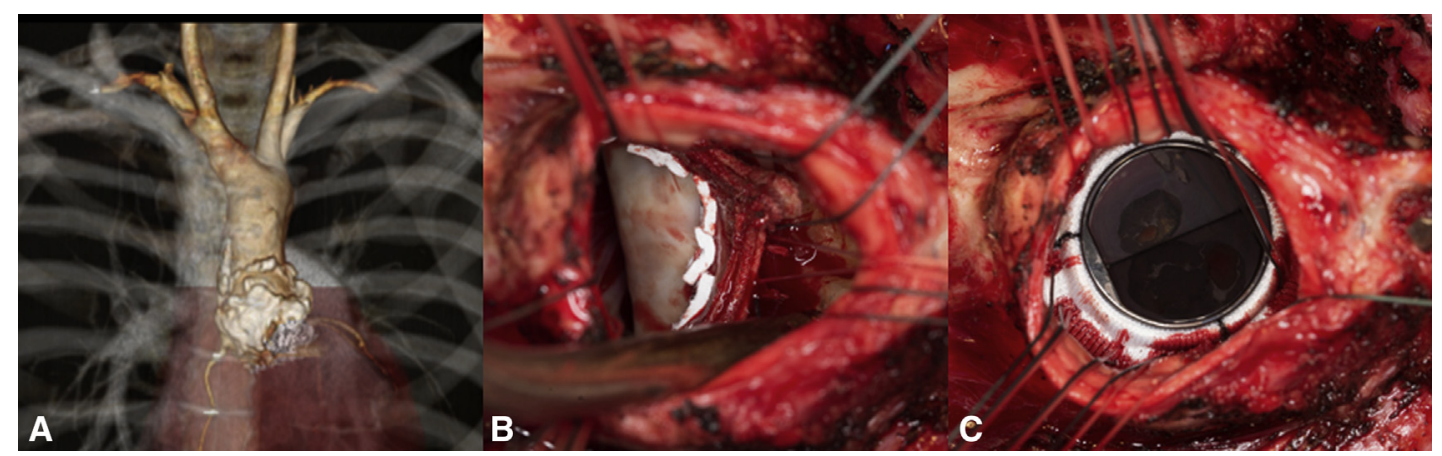

FIGURE 1. A, Calcified aortic root. B, Pledgeted sutures through sewing ring. C, Seated top hat. 


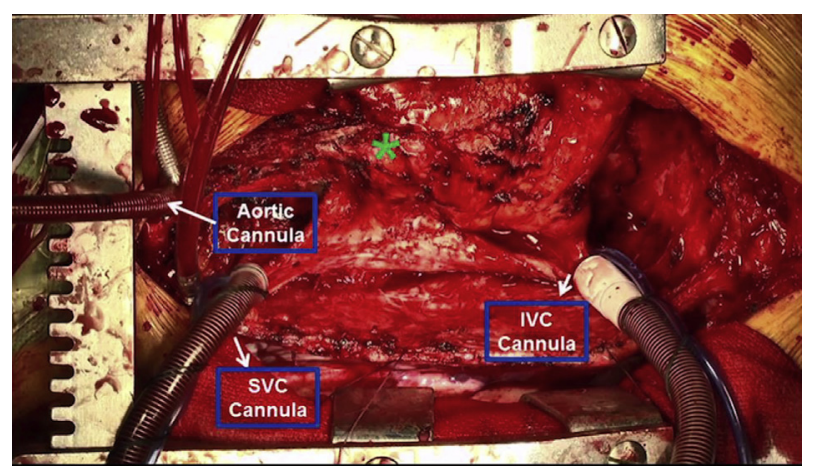

VIDEO 1. Video of surgical valve-on-valve procedure. AVR, Aortic valve replacement; $C E$, Carpentier-Edwards; NYHA, New York Heart Association; $E O A$, effective orifice area; $R C A$, right coronary artery; $I V C$, inferior vena cava; $S V C$, superior vena cava; $P O D$, postoperative day; $A S A$, aspirin; $T E E$, transesophageal echocardiography; $L V O T$, left ventricular outflow tract; CTA, computed tomographic angiography. Video available at: http://www.jtcvsonline.org/article/S0022-5223(17)32482-0/fulltext.

root re-replacement. Instead, the existing bioprosthetic leaflets were excised, and a 21-mm CarboMedics Top Hat valve (LivaNova, London, UK) was placed inside the frame of the 25-mm Carpentier-Edwards sewing ring (valve-on-valve fashion) with 2-0 Ethibond sutures (Ethicon, Inc, Somerville, $\mathrm{NJ}$ ) in horizontal mattress fashion with pledgets on the ventricular side (Figure 1, $B$ and $C$, and Video 1). We believed that a $21-\mathrm{mm}$ valve would avoid patient prosthesis mismatch, which was a concern because of his body mass index of $19.1 \mathrm{~kg} / \mathrm{m}^{2}$ and body surface area of $1.63 \mathrm{~m}^{2}$. Leaflet mobility was satisfactory, and both coronary ostia were visualized. The aorta was closed in end-to-end fashion.

The postoperative course was uneventful, with dismissal on the sixth postoperative day. A chest roentgenogram (Figure 2, A) reveals a magnified view of the valve- on-valve. A dismissal transthoracic echocardiogram revealed an aortic valve gradient of $16 \mathrm{~mm} \mathrm{Hg}$, no periprosthetic regurgitation, and no left ventricular outflow tract obstruction. Cardiac computed tomographic angiography revealed normal motion of the prosthetic leaflets with no perivalvular leak (Figure 2, B). The patient was dismissed on a regimen of coumadin and aspirin.

\section{DISCUSSION}

Reoperation on the aortic root, $\mathrm{AV}$, or ascending aorta after previous surgical intervention constitutes a peculiar subgroup of procedures believed to carry higher surgical risk because of their complexity and variability in anatomic features. ${ }^{1}$ Contemporary series, however, indicate that operative re-intervention in this patient population is justifiable given acceptable operative mortality and long-term survival. $^{2}$

Surgical management of the hostile (calcific) aortic root in the setting of re-recurrent severe bioprosthetic AV stenosis can be approached with a variety of surgical options: (1) transcatheter aortic valve replacement, (2) rapid-deployment aortic bioprosthesis, (3) standard re-replacement of the root with valved conduit, and (4) apicoaortic conduit. Transcatheter aortic valve replacement or rapid-deployment aortic bioprosthesis, such as the Edwards INTUITY valve system (Edwards Lifesciences Corp, Irvine, Calif) did not appeal to either the patient or the cardiovascular surgeon because of concerns of valve longevity. Re-replacement of the aortic root with a classic or modified Bentall procedure requires an extensive reconstruction after taking down the entire calcified root, resulting in prolonged cardiopulmonary bypass and increased morbidity and mortality. In our case, the aortic root and annulus were severely calcific, Bentall reconstruction appeared risky and excessive. Another option in the hostile

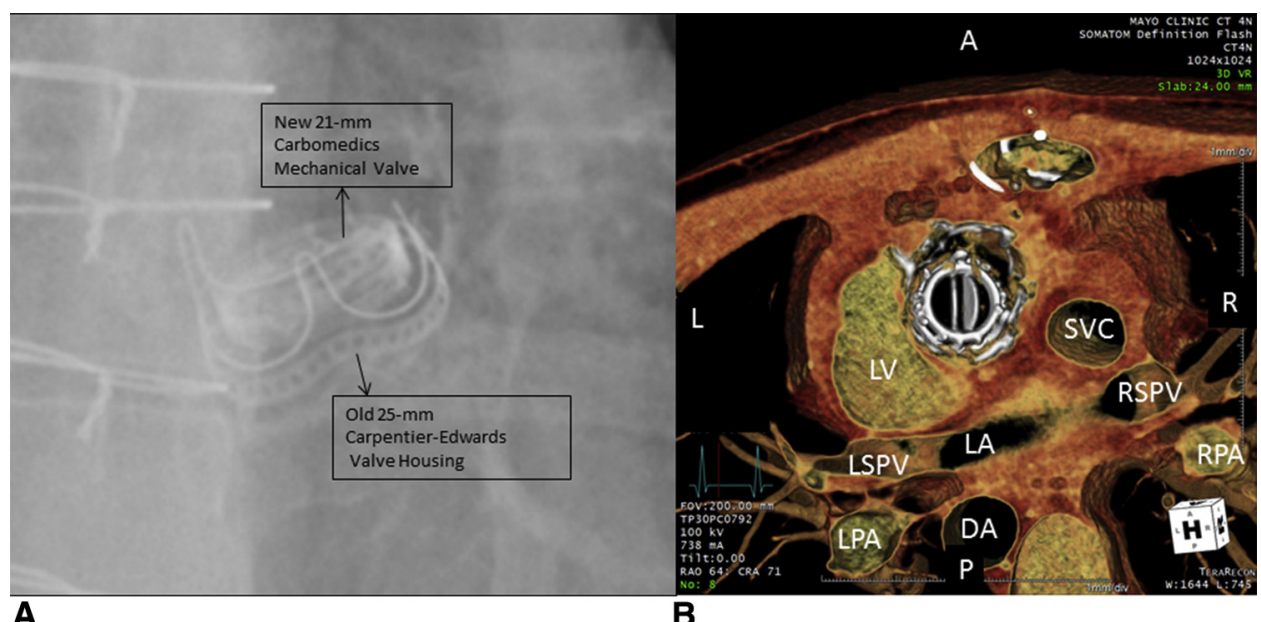

FIGURE 2. A, Chest roentgenogram. B, Functional aortic valve leaflets on cardiac computed tomographic angiography. $A$, Anterior; $L$, left; R, right; $L V$, left ventricle; $S V C$, superior vena cava; $R S P V$, right superior pulmonary vein; $L S P V$, left superior pulmonary vein; $L A$, left atrium; $R P A$, right pulmonary artery; $L P A$, left pulmonary artery; $D A$, descending aorta; $P$, posterior. 
setting is an apicoaortic conduit. The advantages of this approach include avoidance of sternal reentry, cardiopulmonary bypass, valve débridement, and conduction system injury. The disadvantage is the paucity of data regarding long-term ventricular performance, conduit flow with time, and high postoperative mortality rate.

A less conventional approach in the hostile setting involves excision of the prosthetic $\mathrm{AV}$ leaflets and insertion of a new AV prosthesis within the sewing ring of the old valve. Geha and colleagues ${ }^{3}$ described this technique in an early series of 50 patients with degenerated bioprosthesis in the aortic and mitral positions, with no significant gradients detectable on echocardiographic follow up. This technique has undergone a variety of iterations, including unhinging mechanical leaflets from $\mathrm{AV}$ prosthesis for insertion of a bioprosthetic valve ${ }^{4}$ to inserting a valved conduit onto a bioprosthesis sewing ring for treatment of ascending aneurysm that developed after AV replacement. ${ }^{5}$ We found this less conventional "valve-on-valve" approach to be a useful and effective bail-out procedure that offers reduced bleeding potential, crossclamp and cardiopulmonary bypass times, and coronary manipulations in a complex reoperative group of patients and believe that it should be part of the cardiac surgical armamentarium.

\section{References}

1. Silva J, Maroto L, Carnero M, Vilacosta I, Cobiella J, Villagrán E, et al. Ascending aorta and aortic root reoperations: are outcomes worse than first time surgery? Ann Thorac Surg. 2010;90:555-60.

2. Kirsch M, Radu NC, Mekontso-Dessap A, Hillion ML, Loisance D. Aortic roo replacement after previous surgical intervention on the aortic valve, aortic root, or ascending aorta. J Thorac Cardiovasc Surg. 2006;131:601-8.

3. Geha AS, Massad MG, Snow NJ. Replacement of degenerated mitral and aortic bioprosthesis without explantation. Ann Thorac Surg. 2001;72:1509-14.

4. Vricella LA, Cameron DE. Facile conversion from mechanical to bioprosthetic composite aortic root replacement. J Thorac Cardiovasc Surg. 2007;133:565-7.

5. Kurisu K, Ochiai Y, Kajiwara T, Kumeda H, Tominaga R. A modified valve-onvalve approach for aortic root replacement. Ann Thorac Surg. 2003;76 2099-101. 